\title{
Rust Evolution and Electrochemical Properties of Field-exposed Carbon Steel in a Tropical Marine Environment
}

\author{
Daming Chen ${ }^{1,2, *}$, Xinyan Chen ${ }^{2}$, Shaodong Chen ${ }^{2}$, Yong Chen ${ }^{1,2}$ \\ ${ }^{1}$ Key Laboratory of Tropical Biological Resources of Ministry of Education, Hainan University, \\ Haikou, 570228, China \\ ${ }^{2}$ College of Materials and Chemical Engineering, Hainan University, Haikou, 570228, China \\ *E-mail: daming_chen@163.com
}

doi: $10.20964 / 2018.08 .02$

Received: 11 November 2017 / Accepted: 23 March 2018 / Published: 5 July 2018

\begin{abstract}
The corrosion behavior of carbon steel (CS) exposed in a tropical marine atmosphere for 2 years was studied by the weight loss, scanning electron microscopy (SEM), X-ray diffraction (XRD), Raman spectroscopy, and electrochemical impedance spectroscopy techniques. The results show that the corrosion layer became more loose and thick with increasing exposure time, and after 2 years exposure, the rust layer developed into the dual-layer structure. The XRD and Raman analyses confirmed that the corrosion products contained $\gamma-\mathrm{FeOOH}, \alpha-\mathrm{FeOOH}, \gamma-\mathrm{Fe}_{2} \mathrm{O}_{3}$, and $\mathrm{Fe}_{3} \mathrm{O}_{4}$. The polarization curves show that the corrosion potentials $\left(\mathrm{E}_{\text {corr }}\right)$ and corrosion current densities $\left(\mathrm{I}_{\text {corr }}\right)$ changed with increasing exposure duration. Furthermore, an equivalent circuit is proposed for modeling the impedance data, and the charge transfer resistance $\left(R_{2}\right)$ decreased with exposure time during 6 months and increased from 6 months to 24 months, demonstrating that the corrosion rate increased first and then decreased with exposure time.
\end{abstract}

Keywords: Carbon steel; Corrosion behavior; Rust evolution; Electrochemical properties; Tropical marine environment

\section{$\underline{\text { FULL TEXT }}$}

(C) 2018 The Authors. Published by ESG (www.electrochemsci.org ). This article is an open access article distributed under the terms and conditions of the Creative Commons Attribution license (http://creativecommons.org/licenses/by/4.0/). 